\title{
Feasibility Study on the Minimum Quantity Lubrication in High-Speed Helical Milling of Ti-6Al-4V*
}

\author{
Xuda QIN**, Linjing GUI**, Hao LI**, Bin RONG***, Dongsheng WANG***, \\ Hongzhou ZHANG*** and Gaocheng ZUO*** \\ **Tianjin Key Laboratory of Equipment Design and Manufacturing Technology, Tianjin University \\ 300072, Tianjin, China \\ E-mail: qxd@tju.edu.cn \\ ${ }^{* *}$ Shanghai Aircraft Manufacturing Co., Ltd \\ 200436, Shanghai, China
}

\begin{abstract}
The objective of the present work was to study the effect of the application of minimum quantity lubrication (MQL) in high-speed helical milling of Ti-6Al-4V compared with dry and flood coolant (wet) condition. The single factor experiment to study the relationship between cutting force, hole surface roughness and cutting parameters under various coolant-lubricant conditions were implemented. Tool life under various cooling conditions and fixed moderate cutting parameters have also been studied. Uniform flank wear, micro-chipping, thermal cracking and flaking were the dominant tool failure modes under all coolant-lubricant conditions. It was found that dry condition produced the poorest result in terms of cutting force, tool life and hole surface roughness as general expected. MQL presented comparable performance with flood condition in terms of cutting force and hole surface roughness, and even a better tool life performance than flood condition. This testified the flood condition can be replaced by the MQL condition, thus alleviating pollution and saving cost during helical milling of Ti-6Al-4V process.
\end{abstract}

Key words: Helical Milling, Minimum Quantity Lubrication, Titanium Alloys, Cutting Force, Surface Roughness, Tool Wear

\section{Introduction}

Machining of holes by drilling is the most pervasive of all metal cutting processes. Due to its processing characteristics and high accuracy requirement in aeronautical assembly process, drilling nowadays is not suitable for aerospace material machining. An alternative to traditional drilling is helical milling. In helical milling the tool rotates on a helical path and generates the borehole. The kinematics of this process allows drilling different diameters holes with one tool by changing offset value. More advantages of helical milling are: low burr formation, low cutting forces as well as good chip transportation [1].

Iyer. $\mathrm{R}$ et al. [2] presented helical milling is capable of machining $\mathrm{H} 7$ quality holes with a surface finish of $0.3 \mu \mathrm{m} \mathrm{Ra}$ in AISI D2 tool steel. Wang et al. [3] established an analytical cutting force model of the helical milling which can be utilized to predict the change of cutting force in helical milling process under different cutting conditions. Wangyang Ni [4] studied machining dynamics of orbital drilling and tooling solutions for orbital drilling of aerospace aluminum alloy, titanium alloy, CFRP materials and their compounds, which will help the users to select proper cutting tools and cutting parameters

*Received 9 May, 2012 (№. 12-0204) [DOI: $10.1299 / j a m d s m .6 .1222]$

Copyright $\mathbb{C} 2012$ by JSME 
for their specific applications.

Although so many advantages helical milling has, high speed milling of titanium alloy inherently generates high cutting zone temperature due to titanium alloy has an quality of high chemical reactivity on tool materials, high temperature strength, relatively low modulus of elasticity, and low thermal conductivity [5]. Such high temperature causes chips easily to weld to drills and leads to premature tool failure. Besides, high cutting zone temperature also impairs the surface integrity of the holes by inducing tensile residual stresses and surface and subsurface microcracks in addition to rapid oxidation and corrosion [6][7]. In order to reduce cutting temperature and lubricate the sliding surface during machining, cutting fluid is usually adopted [8]. Nevertheless, it should be noted that the application of copious amount of fluid during intermittent cutting could cause a large fluctuation of cutting temperature. This in turn leads to thermal shock and could initiate thermal cracks of the cutting edge and eventually tool failure due to edge fracture [9][10][11]. Besides, when inappropriately handled, cutting fluids may pollute environment. Several research workers state that the costs related to cutting fluids are frequently higher than those related to cutting tools [12]. In order to alleviate the aforementioned negative effects, the idea of minimum quantity lubrication(MQL) which uses a very small amount of oil mixed with copious amount of high pressure air in machining has been adopted. Some good results have been obtained with this technique applied in titanium alloy machining.

Su. Y et al. [13] conducted extensive high speed end milling of Ti-6Al-4V experiments under various cooling and lubrication conditions up to $400 \mathrm{~m} / \mathrm{min}$. As the results have shown, compressed cold nitrogen gas exhibited superior tool life performance over other coolant-lubricant methods. They noted that the flood coolant was unsuitable for high speed machining due to the poor tool life. Liao. Y. S. [14] studied MQL in high-speed end milling of NAk80 hardened steel by coated carbide tool. Results show cutting under flood cooling condition resulted in the shortest tool life due to severe thermal cracks while the use of MQL leads to the best performance, and application of MQL also improved machines surface finish in high-speed milling of die steels. Rahim. E. A. [15] researched MQL palm oil(MQLPO) as a lubricant in the high speed drilling of Ti-6Al-4V compared with MQL synthetic ester(MQLSE), air blow and flood conditions. It was found that uniform flank wear, micro-chipping, thermal cracking and flaking were the dominant tool failure modes, and also MQLSE and MQLPO gave comparable performance with the flood conditions. In addition, MQLPO outperformed MQLSE on the cutting forces and temperature. Hiroyuki SASAHARA [16] studied helical milling holes of aluminum alloy with application of MQL. The results showed that the shape error and burr formation were decreased, machining temperature became lower and the cutting force became smaller compared with that of drilling process. Shape error by helical feed milling with MQL is comparable with flood coolant.

Recently, there are few researches on MQL applied in helical milling titanium alloy, and amounts of experiments have to be done to study its wear and lubricate mechanisms, so the research in this paper is necessary and imperative.

The objective of the present work is to study if the application of MQL could be utilized effectively in high-speed helical milling of Ti-6Al-4V with the use of coated carbide tool compared with dry, flood conditions. Tool life and machined surface roughness under various cutting conditions are evaluated. SEM micrograph and EDAX analysis are also used to investigate the cutting behaviors of MQL.

\section{Experimental setup}

In this paper helical milling operations were performed on DMC75Vlinear 5-axis high speed machining center. And helical milling motion realized by motion compensation of machining center. The experimental conditions are given in Table 1. The Shell Dromus BL 
water-soluble coolant (external) in a flow rate of $1,200,000 \mathrm{ml} / \mathrm{h}$ was used as the cutting fluids under flood coolant condition. Less viscous palm oil was adopted as MQL oil. The MQL oil mist was supplied with an external micro lubricating system (IMQL 119S ) in a very small amount of flow rate $(10 \mathrm{ml} / \mathrm{h})$ at a pressure of $0.5 \mathrm{MPa}$. Oil-mist was ejected through two nozzles settled outside of the cutting zone as shown in Fig.1. The inner diameter of the nozzle was $2 \mathrm{~mm}$.

Table 1. Experimental conditions

\begin{tabular}{ll}
\hline Machine tool & DMC75Vlinear 5-axis high speed machining center \\
\hline Workpiece material & $\begin{array}{l}\text { Ti-6Al-4V (thickness of } 10 \mathrm{~mm} \text {, length of } 250 \mathrm{~mm}, \\
\text { and width of } 120 \mathrm{~mm})\end{array}$ \\
\hline Process parameters & $2500,3000,4000$ and $5000 \mathrm{rpm}$ \\
Speedle speed, $N$ & $0.10,0.15,0.20$ and $0.25 \mathrm{~mm}$ \\
Axial feed per helical revolution, $a_{p}$ & $0.03,0.04,0.05$ and $0.06 \mathrm{~mm} /$ tooth \\
Tangential feed per tooth, $f_{z t}$ & Palm oil (external, two nozzles) \\
\hline MQL & $0.5 \mathrm{MPa}$ \\
Outlet air pressure & $10 \mathrm{ml} / \mathrm{h}$ \\
Lubricant flow rate & $10000 \mathrm{l} / \mathrm{h}$ \\
Outlet air flow & Shell Dromus BL water-soluble coolant (external) \\
\hline Flood coolant & $1,200 \mathrm{l} / \mathrm{h}$ \\
Lubricant flow rate &
\end{tabular}

The milling trials were conducted on Ti-6Al-4V with thickness of $10 \mathrm{~mm}$, length of 250 $\mathrm{mm}$, and width of $120 \mathrm{~mm}$. The through holes with a diameter of $10 \mathrm{~mm}$ are helical milled with $\mathrm{CrN}$ coated solid carbide end mills featuring four teeth, an overall length of $70 \mathrm{~mm}$, an cutting edge length of $14 \mathrm{~mm}$, a diameter of $6 \mathrm{~mm}$, a helix angle of $30^{\circ}$ and a rake angle of $12^{\circ}$, as shown in Fig.2. The workpiece material was mounted on a piezo-electric dynamometer (Kister 9257B) as shown in Fig.1. The dynamometer was connected to the charge amplifier and data acquisition system to measure thrust force and torque data. These experiments were all taken twice and all the data were measured twice before the average value were calculated.

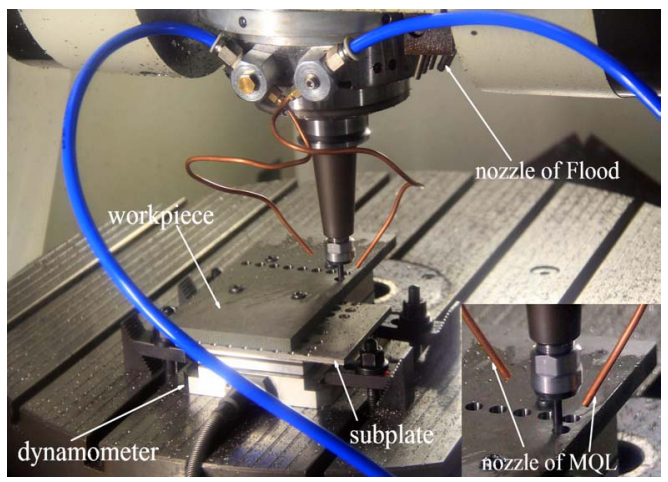

Fig.1. Photographic view of the experimental setup

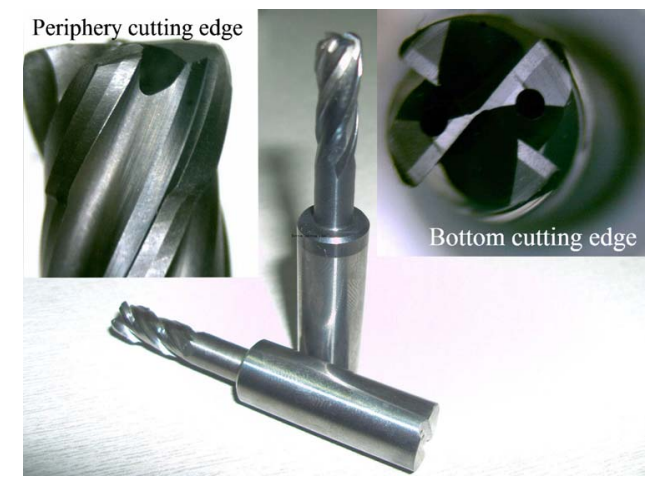

Fig.2. The feature of the helical milling tool

The experiments include two parts, one part is single factor experiments to study the variation trend of cutting force and machined surface roughness by varying one cutting parameter while keeping the other two cutting parameters fixed under various coolant conditions, the other part is tool wear experiment under fixed cutting parameters. In single factor experiment the spindle speed, $N$, was set at 2500, 3000, 4000 and $5000 \mathrm{rpm}$. The axial feed per helical revolution, $a_{p}$, was set at $0.10,0.15,0.20$ and $0.25 \mathrm{~mm}$. The tangential 
feed per tooth, $f_{z t}$, was $0.03,0.04,0.05$ and $0.06 \mathrm{~mm} /$ tooth, respectively. In each group of the experiment, altering one of the three parameters respectively, and then studying the variation of the cutting forces.

The following tool life criteria were adopted during the trials: (i) average flank wear, $\mathrm{VB}_{(\text {ave })}=0.2 \mathrm{~mm}$, (ii) maximum flank wear, $\mathrm{VB}_{(\max )}=0.3 \mathrm{~mm}$, (iii) corner wear $=0.2 \mathrm{~mm}$, (iv) chipping $=0.2 \mathrm{~mm}$, (v) catastrophic failure. The criteria were both applied on bottom cutting edge and periphery cutting edge. The tool wear observation was carried out by SI-DUSB-8-1300k digital microscope after several holes were machined. The observation of microstructures was carried out by using a scanning electron microscopy (SEM), Philips XL-30 with an EDSDX4i system. Further investigation about elemental distribution were carried out by using Energy-dispersive X-ray (EDX). The surface roughness of the machined surface was measured by a Talysurf (Taylor Hobson,UK) using a sampling length of $0.8 \mathrm{~mm}$.

\section{Results and discussion}

\subsection{Cutting force}

In order to understand the effect of spindle speed $(N)$, tangential feed per tooth $\left(f_{z t}\right)$, and axial feed per helical revolution $\left(a_{p}\right)$, cutting forces in axial direction $\left(F_{z}\right), \mathrm{X}$ direction $\left(F_{x}\right)$, and $\mathrm{Y}$ direction $\left(F_{y}\right)$ were collected by using Kistler type $9257 \mathrm{~B}$ dynamometer. The cutting forces were taken and averaged once the cutting process was at a steady state. The resultant force $\left(F_{r}\right)$ in the plane perpendicular to axial direction was calculated by using equation $F_{\mathrm{r}}=\sqrt{F_{x}^{2}+F_{y}^{2}}$.
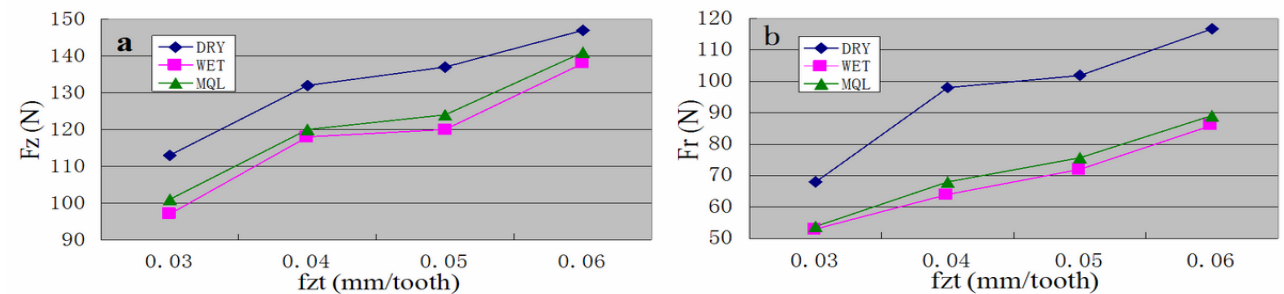

Fig.3. Cutting forces as a function of $f_{z t}$ at $N$ of $3000 \mathrm{rpm}$ and $a_{p}$ of $0.15 \mathrm{~mm} / \mathrm{rev}$ under various cooling-lubricant conditions. (a) cutting forces in axial direction, $F_{z}$; (b) resultant cutting force in the plane perpendicular to axial direction, $F_{r}$.
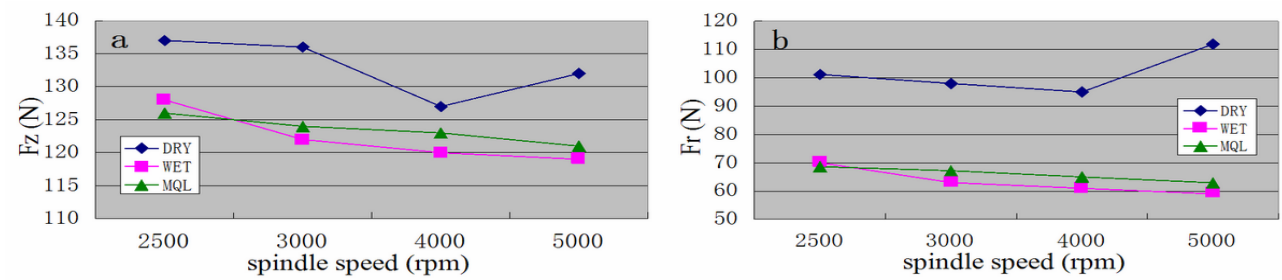

Fig.4. Cutting forces as a function of $N$ at $f_{z t}$ of $0.04 \mathrm{~mm} /$ tooth and $a_{p}$ of $0.15 \mathrm{~mm} / \mathrm{rev}$ under various cooling-lubricant conditions. (a) cutting forces in axial direction, $F_{z}$; (b) resultant cutting force in the plane perpendicular to axial direction, $F_{r}$.
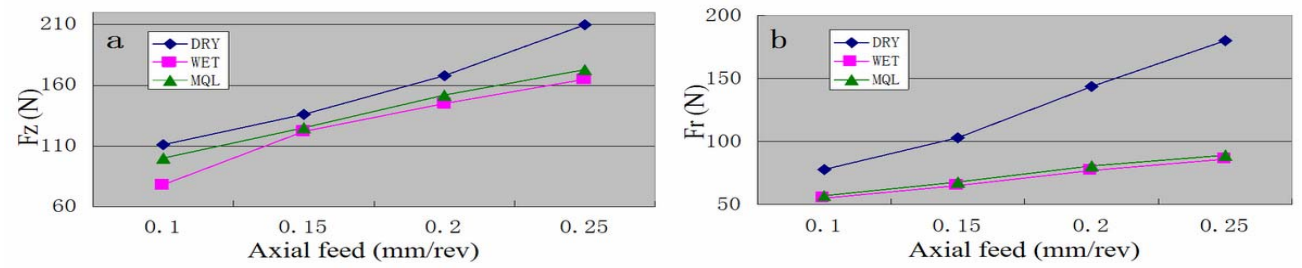

Fig.5. Cutting forces as a function of $a_{p}$ at $N$ of $3000 \mathrm{rpm}$ and $f_{z t}$ of $0.04 \mathrm{~mm} /$ tooth under various cooling-lubricant conditions. (a) cutting forces in axial direction, $F_{z}$; (b) resultant cutting force in the plane perpendicular to axial direction, $F_{r}$. 
Fig.3,4,5 shows the cutting forces as a function of various cutting parameters under various cooling-lubricant methods. It is shown in fig.3a and fig.3b that cutting force rises when the tangential feed per tooth $f_{z t}$ is increased under all cooling-lubricant conditions. The value from the least to the largest is in the order of flood cooling, MQL, Dry condition. And the same trend was observed in fig.5a and fig. $5 \mathrm{~b}$, which presented the cutting force as a function of axial feed per helical revolution $a_{p}$ under various cooling-lubricant conditions. This result was similar to those obtained in the report by Wangyang Ni [4]. This is due to the fact that the cutting force is strongly correlated with the chip thickness, which is associated with the feed rate [14]. While in the fig.4a and fig.4b, an opposite trend was observed, which presented the cutting force as a function of spindle speed $\mathrm{N}$ under various coolant-lubricant conditions. The cutting force declined when spindle speed was increased. This behavior is attributed to the reduction of the contact area at the tool-workpiece interface. Moreover, with the increase in cutting speed, the cutting temperature increases [15], consequently the material hardness and the cutting force were reduced. It is also noted that under dry condition the cutting force curve reversed when the spindle speed increased from $4000 \mathrm{rpm}$ to $5000 \mathrm{rpm}$. The reason of this phenomenon was mainly due to severe adhesion of chips caused by high temperature. In high cutting speed and without cooling method the heat accumulated in the cutting zone quickly and leading to an intense temperature rise [17][18], which was high enough to lead to the severe adhesion and may cause premature tool failure. It was also coincide with the phenomenon observed in the machining process that smoke generated in the cutting area with the speed of $5000 \mathrm{rpm}$ under dry cutting, which proved dry cutting was not suitable for milling titanium alloys.

It is also shown in all the figures that the cutting force under dry condition was much higher than that under MQL and flood conditions, while MQL exhibited an slightly higher cutting force value than flood condition. This could attributed to lubricating ability of palm oil, which is believed to reduce the friction coefficient between the tool-chip and tool-workpiece interfaces. It is also noted that in fig.4a and fig.4b cutting force under flood condition was higher than that under MQL condition when spindle speed was $2500 \mathrm{rpm}$, but when spindle speed rose up to $3000 \mathrm{rpm}$, cutting force under flood condition was less than that under MQL condition. It was in coincidence with report by Rahman et al. [19] that MQL was effective and even better than using cutting fluids especially at low cutting speed , but it seemed to make little improvement on tool performance in the higher cutting speed with respect to flood cooling. However considering environment protection and the cost dealing with cutting fluids, MQL is definitely better than flood cooling.

\subsection{Tool life}

In metal cutting, tool wear depends upon tool-workpiece materials and cutting conditions. The cutting tools in helical milling of titanium alloy, generally fail by gradual wear by abrasion, adhesion, chemical erosion and flaking in bottom cutting edge and periphery cutting edge. Cutting tools may also fail prematurely, randomly under adverse machining conditions (such as dry cutting condition) caused by high temperature, intensive pressure and dynamic loads. In this tool life test experiment part, a group of moderate cutting parameters ( $N$ of $5000 \mathrm{rpm}, a_{p}$ of $0.2 \mathrm{~mm} / \mathrm{rev}, f_{z t}$ of $0.04 \mathrm{~mm} /$ tooth) was adopted, and the tool failure modes observed were mostly gradual wear. Those wears aforesaid mainly occurred at the flank surface in both bottom cutting edge and periphery cutting edge. It was interesting to find that the wear at the periphery cutting edge was not as quite severe as that at the bottom cutting edge, and the occurrence time was also much later than that bottom cutting edge. It was coincidence with the result of cutting force measured that the $F_{z}$ was much higher than $F_{r}$. So in this paper take the wear at bottom cutting edge as the tool life criterion. 


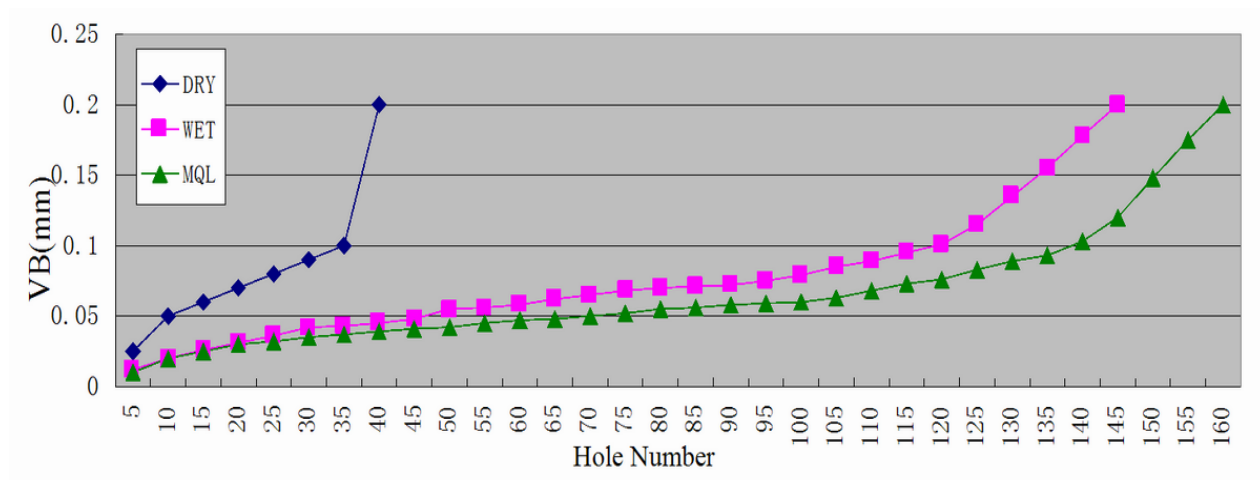

Fig.6. Growth of average principal flank wear, VB with machined holes under dry, wet and MQL conditions.

Fig.6 shows the growth of average flank wear, VB, in bottom cutting edge under dry, flood and MQL conditions. At the very beginning few holes, tool wear started with a relatively faster rate due to what is called break in wear caused by abrasion and micro-chipping at the sharp cutting edge as shown in Fig.7. Then the cutting tools reached a stable wear state that the measured value of VB increased gradually. But after this period, the tool wear developed dramatically, and finally led to tool failure. The result of dry condition shows that the flank wear grew rapidly and cutting edge suffered from excessive chipping. Compared with flood and MQL cutting, a distinct short tool life was obtained under dry cutting, under which can only drill 40 holes, while it was easy to excess 100 holes under MQL cutting and flood cooling cutting. Under dry condition, excessive heat was generated in the cutting zone, especially the tool-workpiece interface, which weakened the cutting edge, leading to quick tool wears and tool failure. Compared to dry cutting, the tool wear was gradual and grew progressively under MQL and flood condition. It was observed that the tool wear rate under MQL condition was lower than that under flood condition. A tool life of 160 holes was recorded under MQL condition, longer than 145 holes under flood condition. This phenomenon can be attributed to the superior cooling-lubricating effect of MQL cutting and occurrence of thermal cracks on the cutting edge under flood cutting caused by thermal shock which results from severe heat variation during high speed intermittent cutting. It was reported by Rahim E.A. that fatty acid in palm oil results in prominent improvement of the friction and wear. It is believed that smooth sliding and low friction were obtained due to the reaction between metal oxide layer and the fatty acid, which leading to metal soap formed on the contact surface [15]. The molecular thin film generated under MQL condition helped reduce the friction and heat generation during machining process, and consequently improved the tool wear.

\subsection{Tool wear mechanism}

Tool wear is the result of various loading factors acting on the cutting edge jointly. It is depend upon tool material, workpiece material and cutting conditions. In this tool wear experiment part, all cutting tools were observed under digital microscope and SEM after several holes were machined. Uniform flank wear, micro-chipping, flaking were the main tool failure modes under the observation. Those phenomenons were mainly owing to the tools experienced interrupted cutting during helical milling, which led to fluctuation of thermal and mechanical stresses and finally caused micro-chipping and flaking [15]. Experimental observation showed that adhesion wear, attrition wear and diffusion wear were the dominant tool wear mechanism under all cooling-lubricant conditions in helical milling of Ti-6Al-4V. Those tool wear mechanism act together, influence each other during the tool wear process. So it is meaningless to explain each kind of tool wear mechanism alone. 

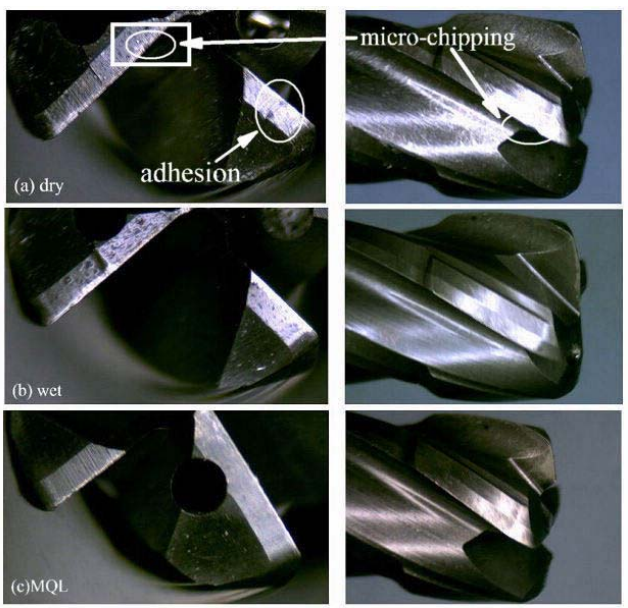

Fig.7. Electron microscope views of initial wear after 20 holes machined under (a)dry, (b)wet, (c)MQL conditions.

The cutting tools after 20 holes machined (5000rpm, $0.2 \mathrm{~mm} / \mathrm{rev}, 0.04 \mathrm{~mm} /$ tooth) under various cooling conditions are shown in Fig.7. Fig.7a shows micro-chipping and adhesion appeared in both bottom cutting edge and periphery cutting edge under dry condition, while the cutting edge was almost new under both wet (flood) condition and MQL condition. This was mainly due to the generation of heat and thermal stress concentration, which was severe under dry cutting condition. Without valid cooling condition, dry cutting produced the highest workpiece temperature [20]. Due to the low thermal conductivity of titanium alloys, the heat was inevitably transferred to the cutting tool, thus weakened the cutting edge. Adhesion had been expected to occur due to titanium alloys apt to weld on the cutting edge during the cutting process. Adhesion was caused by pressure welding between the tool and workpiece interface. During the milling process, the cutting edge suffered from increasing temperature and pressure, hence accelerating the formation of an adhesion layer on the cutting edge [21]. At the beginning of the milling process, the adhered material kept the cutting edge from deformation and rapid wear. With the machining continuing, extensive heat made the adhesion unstable, then tore and carried away the tool material from the cutting edge, and the fresh tungsten carbide substrate would easily get exposure and was more vulnerable to adhesion again as shown in Fig.8, which led to the rapid wear of the tool. Had the machining continues, at last it would lead to severe micro-chipping or flaking.
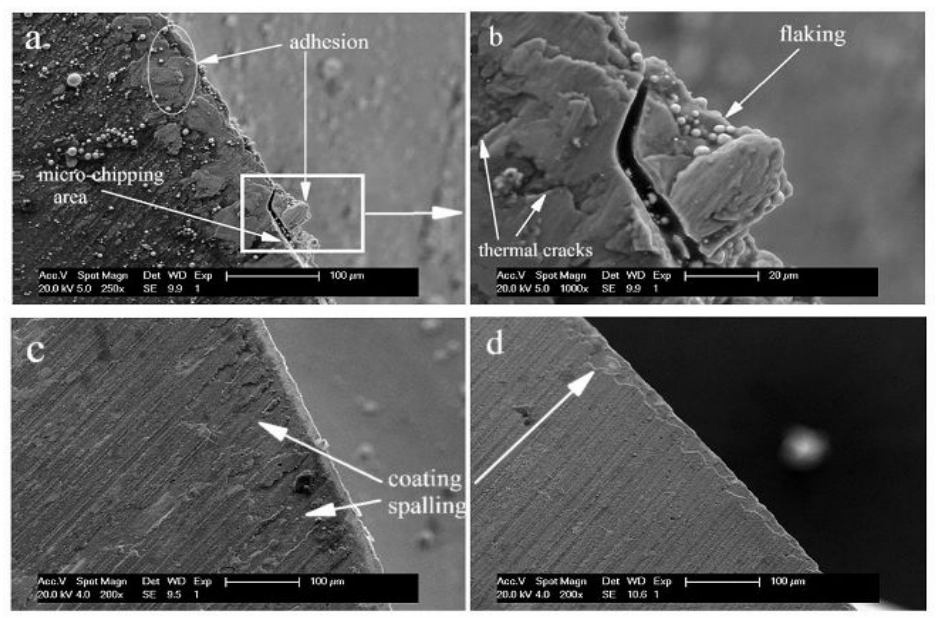

Fig.8. SEM micrographs of bottom cutting edge after 20 holes machined under various cooling condition. (a) magnification of marked area in Fig.7a, dry condition; (b) magnification of marked area in Fig.8a; (c) flood condition; (d) MQL condition; 
Experimental observation on micro-chipping and flaking are shown in Fig.8. and Fig.9. Fig.8a and Fig.8b present the typical adhesion wear mechanism during the tool wear progress process. The poorest tool life of dry cutting in the experiment was mainly due to this wear mechanism, which was not significant for MQL and flood coolant cutting. At the end of tool life, the SEM photographs show that the intensity of workpiece adhered to cutting edge from the least to the largest were in the order of MQL, flood cooling, dry condition. The SEM observation also found that the cyclic adhesion and removal of workpiece material from the cutting edge under MQL condition easily cause attrition wear. Fig.9 shows the typical attrition wear under MQL condition. The attrition wear would take particles of carbide(WC) and cobalt binder(Co) from the worn cutting edge through rubbing between the chip and cutting edge, which accelerated the tool wear.
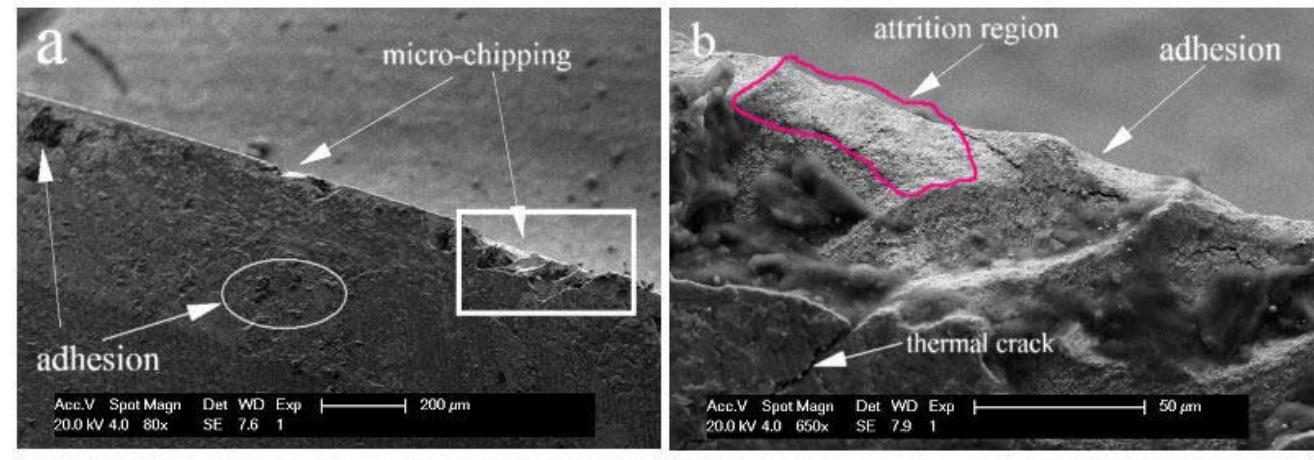

Fig.9. (a) SEM micrographs of periphery cutting edge at the end of tool life under MQL condition.

(b) magnification of marked area in Fig.9a.

Fig.7b also shows workpiece material adhered to cutting edge under flood cooling, which was different with pressure welding under dry cutting. Without high pressure air, the chippings can't all be flushed out by cutting fluid during milling process. Then due to liquid surface tension which caused chips adhere to cutting edge. It would not cause serious damage to cutting edge, but may cause coating spalling and abrasion wear during machining process by sliding tool-workpiece interface. The abrasion wear mechanism was due to lumps of tool particles or crushed workpiece material sandwiched into the interface between cutting edge and workpiece [22]. The abrasion wear was even severe when the contact was not secure and there was sliding between the tool-chip interface [23]. The experimental observation shows abrasion wear was significant at the region near the periphery of cutting tool under dry and flood cooling cutting as shown in Fig.10. Thermal cracks were also observed under all cutting environments perpendicular to the cutting edge, which was severe under flood cooling condition as shown in Fig.10b. The formation of thermal cracks was owing to fluctuation of temperature at the tool-chip interface, which led to modification of the stress distribution in the cutting zone [24]. The reason of unsatisfactory tool life under flood cooling condition compared with MQL cutting was due to the occurrence of thermal cracks (Fig.9 and Fig.10) on the cutting edge caused by thermal shock, which was triggered possibly by abrasion wear. 

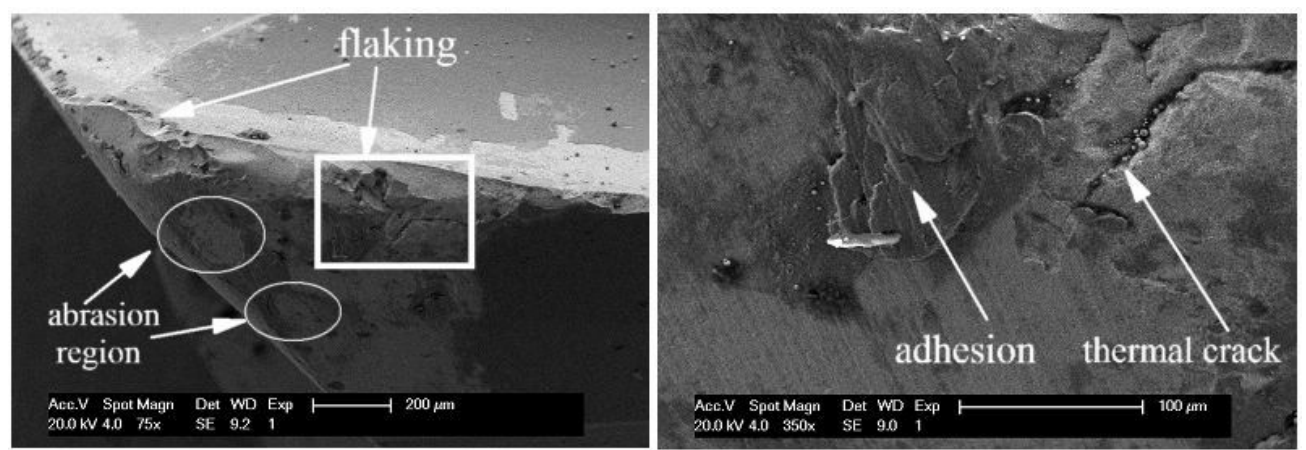

Fig.10. (a)SEM micrographs of periphery cutting edge at the end of tool life under flood condition.

(b) magnification of marked area in Fig.10a.

As shown in Fig.7c, adhesion phenomenon did not appear under MQL cutting and even the cutting edge was almost new after 20 holes were machined compared with other cooling-lubricant conditions. With coolant-lubricant function of MQL, tool can withstand the cyclic thermal load and workpiece material was not easily weld on cutting edge. In addition, high pressure air flow ejected from two nozzles beside the cutting tool can blow out the chips easily. This is one reason that can explain tool life under MQL condition is longer than that of flood condition.

The EDX analysis performed on the flank face of worn bottom cutting edge depicted that diffusion wear and oxidation occurred under all cutting environments with different extent as shown in Fig.11. Under high temperature, carbide(WC) and cobalt binder(Co) from the cutting edge made oxidation reaction with oxygen $(\mathrm{O})$, generating unstable and soft oxide, which was easily rubbed out by adhesion and abrasion. Diffusion wear also occurred under high temperature and high pressure. The diffusion between the cemented carbide tool and titanium alloys embrittled the region of tool where diffusion happened [25]. In this experiment, EDX analysis showed the lowest Ti content and highest $\mathrm{W}$ content on worn cutting edge during MQL cutting, which indicated that diffusion wear was the lowest under MQL compared with dry and flood cutting, thereby pronouncing quite effective lubrication of MQL cutting. Diffusion wear and oxidation wear were the most severe under dry cutting as the figure depicted. This was due to the highest temperature during the cutting zone in dry cutting.

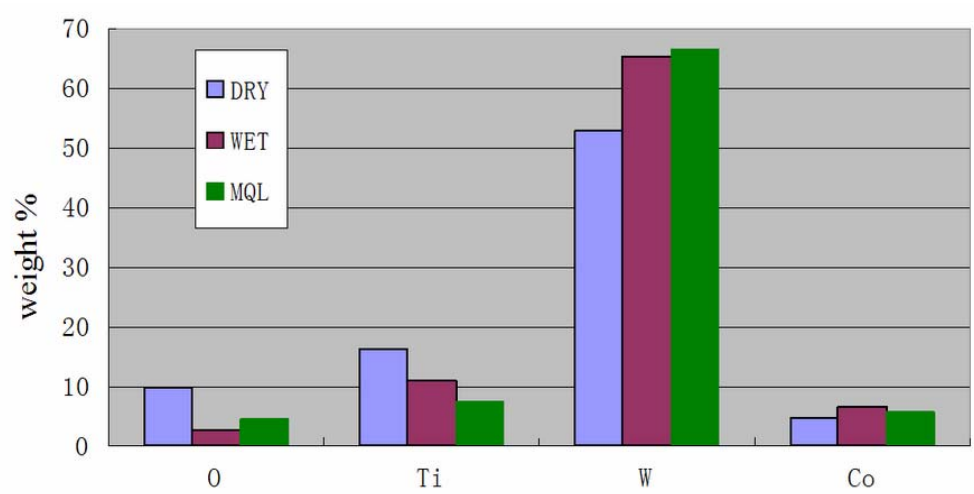

Fig.11 EDAX analyses of worn cutting edge at the end of tool life under various conditions.

\subsection{Workpiece surface roughness}

Fig.12 shows the hole surface roughness $R_{a}$ obtained under various cutting parameters and cutting environments. It is shown that under all coolant-lubricant conditions, the value of $R_{a}$ from least to largest was in the order of flood cooling, MQL, dry condition. MQL 
condition almost showed comparable performance with flood condition. This proved the superior cooling-lubricant ability of MQL condition. The value of surface roughness rose when the tangential feed per tooth $f_{z t}$ or axial feed per helical revolution $a_{p}$ was increased. While cutting speed increased, an opposite trend was observed. The result follows general expectation. But it is notable that the curve reversed when cutting speed rises from 4000 rpm to $5000 \mathrm{rpm}$ under dry cutting shown in Fig. 12b. This is due to serious adhesion caused by high temperature as aforesaid.
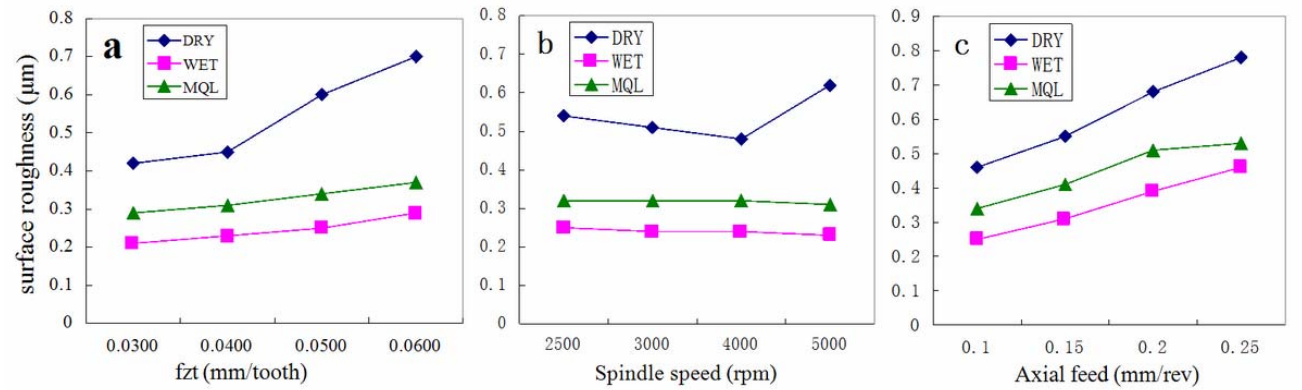

Fig.12. Surface roughness $\left(R_{a}\right)$ as a function of various cutting parameters under various cooling-lubricant conditions. (a) $R_{a}$ as a function of $f_{z t}$ at $N$ of $3000 \mathrm{rpm}$ and $a_{p}$ of $0.15 \mathrm{~mm} / \mathrm{rev}$. (b) $R_{a}$ as a function of $N$ at $f_{z t}$ of $0.04 \mathrm{~mm} /$ tooth and $a_{p}$ of $0.15 \mathrm{~mm} / \mathrm{rev}$. (c) $R_{a}$ as a function of $a_{p}$ at $N$ of 3000 rpm and $f_{z t}$ of $0.04 \mathrm{~mm} /$ tooth.

\section{Conclusion}

The feasibility of MQL in helical milling of Ti-6Al-4V by coated carbide tool was evaluated in this study. Based on the results of the present experimental investigation the following conclusion can be drawn:

1. The dry condition produced the poorest result in terms of cutting force, tool life and hole surface roughness, while the MQL presented comparable performance to flood condition in cutting force and hole surface roughness.

2. The tool life under MQL condition was 3 times as much as that under dry condition, and MQL exhibited an even better performance than flood cooling in terms of tool life, which testified the superior coolant-lubricant ability of MQL.

3. Uniform flank wear, micro-chipping, thermal cracking and flaking were the dominant tool failure modes in helical milling of Ti-6Al-4V at all coolant-lubricant conditions. All those failure modes appeared and progressed rapidly under dry condition. With the aid of high pressure air, MQL exhibited an distinct advantage in exhausting chips, which postponed the wear progression under MQL condition.

4. The dominant wear mechanism of coated cemented carbide tools in helical milling of Ti-6Al-4V were adhesion, diffusion and attrition wear under all the cooling-lubricant conditions investigated. In additional, thermal cracking was severe under the flood cutting conditions due to severe thermal fatigue wear compared with MQL.

5. In the helical milling of Ti-6Al-4V, the performance of MQL is comparable with using flood coolant, which shows the flood condition can be replaced by the MQL condition, thus alleviating pollution and saving cost.

\section{Acknowledgements}

This work was partially supported by the National Natural Science Foundation of China (51275345), Natural Science Foundation of Tianjin (11JCZDJC22800), Seed Foundation of Tianjin University, and National Engineering and Research Center for Commercial Aircraft Manufacturing (SAMC11-JS-07-215). 


\section{References}

(1) Qin, X.D., Chen, S.M., and Liu, W.C., Development and application of helical milling technology in the aviation manufacturing and assembly industry, Aeronaut Manuf Technol, (in Chinese) No.6, (2009) pp.58-60.

(2) Iyer, R., Koshy, P., and Ng, E., Helical milling: an enabling technology for hard machining precision holes in AISI D2 tool steel, Int J Mach Tools Manuf, No.47, (2007) pp.205-210.

(3) Wang, H.Y., Qin, X.D., Ren, C.Z., and Wang, Q., Prediction of cutting forces in helical milling process, Int J Adv Manuf Technol, No.58, (2012) pp.849-859

(4) Wang, yang. Ni., Orbital Drilling of Aerospace Materials, SAE International, (2007)

(5) H. Hong., A.T. Riga., J.M. Cahoon., and C.G. Scott., Machinability of steels and titanium alloys under lubrication, Wear, No.162, (1993) pp.34-39.

(6) P. Leskover., and J. Grum., The metallurgical aspect of machining, Annals of CIRP, Vol.35, No.1, (1986) pp.537-550.

(7) H.K. Tonshoff., and E. Brinkomeier., Determination of the mechanical and thermal influences on machined surface by microhardness and residual stress analysis, Annals of CIRP, Vol.29, No.2, (1986) pp.519-532.

(8) F. Klocke., G. Eisenblatter., Dry cutting, Annals of CIRP, Vol.46, No.2, (1997) pp.519-526.

(9) M.C. Shaw., Metal Cutting Principles, second ed., Oxford, New York, (2005) pp.64-69.

(10) M.A. Elbestawi., L. Chen., C.E. Becze., and T.I. EI-Wardany., High speed milling of dies and models in their hardened state, Annals of CIRP, Vol.46, No.1, (1997) pp.57-62.

(11) J.M. Vieira., A.R. Machado., and E.O. Ezugwu., Performance of cutting fluids during face milling of steels, Journal of Materials Processing Technology, No.116, (2001) pp.244-251.

(12) G. Byrne., and E. Scholta., Environmentally clean machining processes-a strategic approach, Annals of CIRP, Vol.42, No.1, (1993) pp.471-474.

(13) Su. Y., He. N., Li. L., and Li. X.L., An experimental investigation of effects of cooling/lubrication conditions on tool wear in high speed end milling of Ti-6Al-4V, Wear, No.261, (2006) pp.760-766.

(14) Liao. Y.S., Lin. H.M., and Chen. Y.C., Feasibility study on the minimum quantity lubrication in high-speed end milling of NAK 80 hardened steel by coated carbide tool, Int J Mach Tools Manuf, Vol.47, (2007) pp.1667-1676.

(15) Rahim. E. A., and Sasahara. H., A study of the effect of palm oil as MQL lubricant on high speed drilling of titanium alloys, Tribology International, Vol.44, No.3, (2011) pp.309-317.

(16) Hiroyuki. SASAHARA., Makoto. KAWASAKI., and Masaomi. TSUTSUMI., Helical Feed Milling with MQL for Boring of Aluminum Alloy, Journal of Advanced Mechanical Design, Systems, and Manufacturing, Vol.2, No.6, (2008) pp.1030-1040.

(17) Shane. Y. Hong., and Yucheng. Ding., Cooling approaches and cutting temperatures in cryogenic machining of Ti-6Al-4V, Int $J$ Mach Tools Manuf, No.41, (2001) pp.1417-1437.

(18) Mustafizur. RAHMAN., Yoke. San. WONG., and A. Rahmath. ZAREENA., Machinability of Titanium Alloys, Int J Series C-Mechanical Systems Machine Elements and Manufacturing, Vol.46, No.1, (2003) pp.107-115.

(19) M. Rahman., A. Senthil, Kumar., and M.U. Salam., Experimental evaluation on the effect of minimal quantities of lubricant in milling, Int J Mach Tools Manuf, Vol.42, (2002) pp.539-547.

(20) R.P. Zeilmann., and W.L. Weingaertner., Analysis of temperature during drilling of 
Ti-6Al-4V with minimal quantity of lubricant, Journal of Materials Processing Technology, Vol.179, (2006) pp.124-127.

(21) Nouari. M., List. G., Girot. F., and Gehin. D., Effect of machining parameters and coating on wear mechanisms in dry drilling of aluminium alloys, Int $J$ Mach Tools Manuf, Vol.45, (2005) pp.1436-1442.

(22) Ezugwu. E.O., and Wang. Z.M., Titanium alloys and their machinability-a review. $J$ Mater Process Technol, Vol.68, (1997) pp.262-274.

(23) Gokende. O., and Subramaniam. S.V., Tribology of tool-chip interface and tool wear mechanism, Surf Coat Technol, Vol.149, (2002) pp.151-160.

(24) Jawaid. A., Sharif. S., and Koksal. S., Evaluation of wear mechanisms of coated carbide tools when face milling titanium alloy, J Mater Process Technol, Vol.99, No.1-3, (2000) pp.266-274.

(25) Min. W., and Youzhen. Z., Diffusion wear in milling titanium alloys, Materials Science and Technology, Vol.4, (1988) pp.548-553. 